\section{A PESCA ARTESANAL NA GEOGRAFIA BRASILEIRA: IMPACTOS/CONFLITOS, AMBIENTES/TERRITÓRIOS•}

Artisanal fisheries in brazilian geography: impacts/conflicts, environments/territories

\author{
Cristiano Quaresma de Paula * \\ *Pós-doutorando do PPGEO da UFPA - cqpgeo@gmail.com
}

Recebido em 04/06/2019. Aceito para publicação em 10/06/2019.

Versão online publicada em 10/09/2019 (http://seer.ufrgs.br/paraonde)

\begin{abstract}
Resumo:
A pesca artesanal tem sido pesquisada por Geógrafos de diferentes regiões Brasileiras. A sumarização dessas pesquisas permitiu compreender as características da pesca e as possibilidades que a Geografia proporciona para responder às problemáticas dos pescadores. Neste artigo busca-se compreender a relação entre impactos ambientais e disputas territoriais na pesca artesanal brasileira. Para tanto, analisou-se dissertações e teses, onde se identificou impactos que causam a extinção da pesca e por isso a perda de territórios pesqueiros, bem como disputas por territórios entre pescadores e outras atividades econômicas que provocam impactos na natureza. Assim, a análise se coloca sobre o contínuo estabelecido entre "território da natureza e natureza do território".
\end{abstract}

Palavras-chave: Pesca Artesanal. Impactos Ambientais. Disputas Territoriais.

\begin{abstract}
:
The artisanal fishing was researched by geographers from different Brazilian regions. The summarization of these surveys allowed us to understand the characteristics of fishing and the possibilities offered by Geography to respond to fishermen's problems. This article intends to understand the relation between environmental impacts and territorial disputes in Brazilian artisanal fishing. For that, we analyzed dissertations and theses, which identified impacts that cause the extinction of fishing and, therefore, the loss of fishing territories, as well as disputes over territories between fishermen and other economic activities that cause impacts on nature. Thus, the analysis is placed on the continuum established between "territory of nature and nature of territory".
\end{abstract}

Key-words: Artisanal Fishing. Environmental impacts. Territorial Disputes.

\section{Introdução}

Em todo o Brasil inúmeros Geógrafos abordam em seus trabalhos as problemáticas da pesca artesanal. A espacialização desses trabalhos permite pensar a pesca artesanal e a própria geografia brasileira. Esta se configura em uma análise panorâmica (de sobrevoo) que favorece a discussão sobre impactos ambientais e disputas de territórios.

Em vez de polarizar uma abordagem ambiental e uma territorial, como é usual, pretende-se provocar a própria Geografia a pensar conceitos híbridos, que correspondam as problemáticas complexas do mundo real. A proposta é partir do continuo entre o "território da natureza e a natureza do território".

Do ponto de vista metodológico a pesquisa está orientada pelos princípios do pensamento complexo, propostos por Morin (1990). Para a analise considerou-se 71

\footnotetext{
- Artigo originalmente apresentado na XII ENANPEGE.
} 
trabalhos (de 1982 a 2015), sendo eles dissertações de mestrado e teses de doutorado. Desta etapa resultou um banco de dados georreferenciado de dissertações e teses.

Diante do exposto o artigo objetiva identificar abordagens sobre a pesca artesanal na produção acadêmica da Geografia brasileira (dissertações e teses) e analisar espacialmente a relação entre impactos ambientais e disputas por territórios.

\section{Território da Natureza}

Suertegaray (2009) compreende que na leitura ambiental as formas de socialização do uso dos recursos da natureza estão presentes nas marcas deixadas no território pelas técnicas. Assim "Decifrar e mesmo redimensionar essas marcas exigem o reconhecimento de que muito dos problemas ambientais, como ensina Alier, são conflitos ecológicos distributivos ou, na expressão geográfica, territoriais" (p. 24).

$\mathrm{Na}$ modernidade, a natureza foi compreendida, seja pela cultura, política ou economia, como externa ao humano. Logo a "leitura de nossa base filosófica- cientifica se inscreve na necessidade atual de decifrar um mundo extremamente complexo, onde sob muitos aspectos a natureza não é natural" (SUERTEGARAY, 2009A, p. 20).

Milton Santos (2006) compreende que a natureza é socialmente construída. Aponta que a natureza artificializada é uma característica da contemporaneidade, no sistema técnico-científico-informacional. Contudo, os objetos cujos funcionamentos são similares aos da natureza, são compreendidos como abstratos, logo inferiores aos objetos concretos, cujos, mais artificiais, tem perfeição superior do que a natureza. Assim, por meio da técnica, o homem se impõe à natureza.

Entende-se que a intensificação do uso da natureza, por meio da vinculação da ciência à técnica, promove sua subordinação, "num duplo sentido, de um lado a subordinação que degrada e aniquila de outro a subordinação que recria e reinventa a natureza". Nos dois casos, o híbrido se manifesta como objeto densamente tecnificado, concordante com o contexto produtivo e cultural da sociedade contemporânea (SUERTEGARAY, 2002, p. 162).

Nessa compreensão geográfica a natureza, sendo transfigurada, passa a ser outra socializada, instrumentalizada, tecnificada ou cibernética -. Assim, a ótica ambiental da Geografia se distingue da ecológica, pois inclui o homem não como ser naturalizado, mas como um ser social que ao mesmo tempo é produtor e produto de tensões ambientais (SUERTEGARAY, 2001).

Diante disso, e mais especificamente no que tange as comunidades tradicionais, onde se incluem os pescadores artesanais, nas discussões quanto aos impactos ambientais, é fundamental compreender os impactos dessa natureza transfigurada sob os seus modos de viver e as consequências sobre seus territórios.

Entendem-se os territórios da natureza quando distingue, não separa, os pescadores artesanais da sociedade geral pela relação que estabelecem com a natureza, logo sob o ponto de vista ambiental. Essas relações diferenciadas expressam marcas e ao mesmo tempo em que os pescadores deixam suas marcas sofrem os efeitos de marcas "mais intensas" deixadas por outras atividades que se veem desvinculadas do ambiente em que se encontram. Essas marcas que transfiguram a natureza e influem na sua dinâmica resultam na redução da quantidade e qualidade da fauna aquática e, por isso, na extinção de territórios tradicionais pesqueiros. 
Com base nessa discussão será enfatizada a repercussão de impactos ambientais sobre recursos pesqueiros e, pela redução do estoque, extinção de territorialidades tradicionais.

$\mathrm{Na}$ região Norte a organização social da pesca artesanal apresenta distinções. É nessa região onde se apresenta a modalidade "pesca comercial". Distingue-se da pesca artesanal comunitária, pois apresenta determinada subordinação do pescador ao comerciante (dono do barco frigorifico, ou que fornece o gelo) assim como se distingue da pesca industrial, por não utilizar tecnologias tão predatórias. Contudo, a pesca comercial e a comercialização de pescado são apontadas como as maiores causas de impactos ambientais. Isso se deve pela pressão que causam nos recursos, principalmente espécies de alto valor econômico e em vias de extinção como o pirarucu.

A geração de energia também é apresentada como causadora de graves impactos ambientais na região Norte. Neste sentido destacam-se as usinas hidrelétricas que são frequentes na região e provocam alterações significativas nos rios. A mudança no curso dos rios afeta, por exemplo, a piracema dos peixes.

A pesca industrial também ocorre na região, mesmo que em menor frequência do que a comercial. Está associada às indústrias pesqueiras dos grandes centros urbanos da região. Também é responsável pela sobrepesa devido as técnicas utilizadas que geralmente não obedecem as normas vigentes na legislação ambiental.

$\mathrm{Na}$ região Nordeste o Hidronegócio é frequentemente apontado como causa de impactos ambientais. Nesta região a instalação de empreendimentos, sobretudo de carcinicultura, cujas técnicas fazem uso de uma serie de produtos químicos, tem levado a contaminação de corpos d'água e na extinção de espécies pesqueiras.

Acompanhando o processo de modernização, que causa tantos impactos ambientais cabe destacar os causados pela industrialização. Assim, grandes projetos industriais têm acarretado na contaminação do ambiente e consequentemente na qualidade (por vezes extinção) do pescado. A indústria do Petróleo também é apontada como causadora de impactos ambientais, tanto pela instalação dos empreendimentos (plataformas) que provoca mudanças nas características do ambiente, quanto devido a "acidentes" que causam sérios danos a flora e fauna aquática.

A pesca artesanal e a comercialização de pescado também são apontadas como causadoras de impactos, uma vez que nesse cenário de concentração populacional e de atividades econômicas a demanda por frutos do mar é crescente, assim, por incentivo do próprio governo, há o incremento dos apetrechos de pesca, a fim de intensificar as capturas.

$\mathrm{Na}$ região Centro-Oeste a análise foi limitada devido ao número de trabalhos realizados. Há relatos de significativas mudanças na dinâmica dos rios e canais devido a atividade de mineração, que também causa contaminação.

$\mathrm{Na}$ região Sudeste a principal causa de impacto ambiental identificada é a pesca industrial. Cabe destacar que essa indústria tem alta capacidade de captura devido ao uso de apetrechos de pesca modernos e extremamente predatórios. Os trabalhos apontam que a pesca indiscriminada no oceano tem reduzido drasticamente a presença dessas espécies nos estuários e rios, onde predomina a pesca artesanal.

Sendo a região mais industrializada do país também se caracteriza pela situação dos recursos ambientais em estado de degradação. Cabe destacar que em contraste com as restrições impostas pela legislação ambiental esses grandes empreendimentos 
permanecem sendo licenciados e causando grandes impactos. Os portos e barragens instalados na região evidenciam isto. São megaempreendimentos com apoio dos governos a que estão jurisdicionados, que desconfiguram a dinâmica ambiental e que não recuam frente aos movimentos sociais e ambientalistas.

Outros impactos frequentes na região são causados pela agricultura e turismo. A primeira impacta devido a projetos de irrigação que tem reduzido a disponibilidade de água nos pesqueiros, bem como por causa despejo de dejetos contaminados por agrotóxicos. Já a indústria do turismo eleva a pressão sobre o ambiente em que se instala e devido à falta de infraestrutura provoca degradação. Além de poluir o ambiente, o setor de turismo demanda mais pescado o que provoca a intensificação da atividade pesqueira e o uso de equipamentos mais predatórios.

$\mathrm{Na}$ região Sul o agronegócio se destaca como causador de impacto ambiental. Ressaltam-se as outorgas de direitos de uso de águas públicas por grandes projetos de irrigação e a poluição dos recursos hídricos por efluentes agrícolas contaminados por agrotóxicos.

A industrialização também se evidencia nos trabalhos como causadora de impacto ambiental. A instalação de grandes projetos industriais têm esgotado os recursos ambientais presentes, sobretudo água e solo. A contaminação resulta na perda de qualidade dos peixes e, por vezes, em eventos de elevada mortandade destes. Dentro do que é chamado de modernização insere-se também a urbanização. Neste caso é apontado o crescimento das cidades sem o desenvolvimento de estruturas de saneamento correspondentes à demanda, que tem extinguido a pesca em determinados rios. Além disso, a urbanização aumenta a demanda por pescado, o que provoca na maior exploração dos recursos pesqueiros locais.

Nesta região a pesca industrial está muito presente e compete frequentemente pelos mesmos recursos que a pesca artesanal. As características das embarcações e dos apetrechos implicam em uma pescaria extremamente predatória em comparação à praticada pelos pescadores artesanais. Outra atividade presente na região e que provoca impactos ambientais é a mineração, que causa mudanças nas características hidrológicas dos pesqueiros.

\section{A Natureza do Território}

Com destaca Saquet (2010) o território é espaço de vida e fonte de recursos. Essa natureza conceitual permite discutir o território das comunidades de pescadores, que inclui pesqueiros, áreas de moradia e socialização. Estes territórios contêm recursos que interessam a outras atividades econômicas (potencial energético, minérios, paisagem, etc.).

Diegues (2004, p. 203-205) concorda ao afirmar que os recursos pesqueiros são móveis e que estabelecer e manter limites e divisas não é tarefa fácil. Acrescenta que, na concepção dos membros das comunidades de pescadores artesanais, o território marinho é mais amplo e fluido do que o estritamente terrestre. Assim, a territorialidade do mar não se faz sem conflitos entre os comunitários e com outros atores que disputam o território.

Raffestin emprega à dimensão política quando vê o território de forma relacional, ou seja, como produto de uma dada coletividade (SAQUET, 2010, p. 78). Contudo, se o termo prisão se refere ao controle do espaço, o território não se restringe a um conjunto 
de relações de poder. Na amplitude da proposta de Raffestin, o território é composto por diversas dimensões (HAESBAERT, 2007, p. 84).

Entende-se a delimitação de territórios como produto do desejo e da necessidade de sobrevivência e representa todo um conjunto de fatores, dos quais uns são físicos, outros humanos: econômicos, políticos, sociais e/ou culturais (RAFFESTIN op. cit. SILVA, 2006, p. 55).

Acrescentamos que os territórios são construídos e desconstruídos nas mais diferentes escalas espaciais e temporais, em um campo de forças onde se manifestam relações de poder espacialmente delimitadas (SOUZA, 1995). Logo, o território deve ser abordado de acordo com os contextos históricos e geográficos em que foi produzido. Logo, interessa tanto como articulador de conexões ou redes em escala global, quanto como uma área-abrigo e fonte de recursos, em escala local (HAESBAERT, 2007, p. 97).

Para Raffestin (1993) a territorialidade humana, "é um conjunto de relações efetivado pelos homens, como membros de um grupo social e com exterioridade". Essas relações são mediadas pelas línguas, religiões e tecnologias. As relações humanas são simbólicas e materiais (SAQUET, 2010, p. 79). A territorialidade não exige uma área definida, envolve estratégia de influência e a delimitação só cria território se as fronteiras afetam o comportamento ou controlam o acesso (Ibidem, p.84).

Haesbert (2007, p. 86) ressalta que apesar de Sack centralizar-se na perspectiva política, reconhece também as dimensões: econômica e cultural da territorialidade, intimamente ligada ao modo como as pessoas utilizam a terra, como elas próprias se organizam no espaço e como elas dão significado ao lugar. Assim, Robert Sack (1986) define a territorialidade humana como a tentativa de um indivíduo ou grupo de afetar, influenciar ou controlar pessoas, fenômenos e relações, através da delimitação e da afirmação do controle sobre um território.

A territorialidade pesqueira artesanal se expressa como estratégias de influência ao acesso dos pesqueiros; estas influências se dão por meios materiais e imateriais, podendo ser mantidas por ações não territoriais. Devido ao recurso pesqueiro não ser fixo no espaço, as territorialidades na pesca são descontínuas e móveis, sendo que se mantém enquanto há produtividade. Essas territorialidades ensejam identidades territoriais tradicionais, devido ao vínculo territorial estabelecido entre o pescador e 0 ambiente que, no caso dos pesqueiros, é fonte de recursos e espaço de vida (DE PAULA, 2013).

Considerando que a pesca artesanal ocorre em corpos d'água que têm diversos usos, destaca-se que os conflitos pelos territórios pesqueiros não se dão somente entre pescadores. Esse contexto agrava a crise ambiental na pesca artesanal, uma vez que outras atividades econômicas desconhecem ou negam os territórios das comunidades locais e destroem pesqueiros tradicionais.

Nesse momento serão expostos contextos em que os territórios das comunidades tradicionais de pescadores artesanais são disputados pela pesca industrial e por outras atividades econômicas.

Na região Norte o principal conflito por território é fundiário. As comunidades resistem à grilagem de terras e desapropriação promovida por agentes privados e públicos que visam à instalação de grandes projetos na região Amazônica. Compreendendo que o território pesqueiro é agua "onde está o recurso pesqueiro" e terra "onde está a comunidade" essa problemática dialoga com aqueles que abordam a questão agrária, sobretudo a relação entre pequenos agricultores e latifundiários. 
A pesca comercial também gera conflito por territórios pesqueiros, na medida em que são alteradas as relações sociais entre os pescadores. Os comerciantes de pescado provocam cisões nas comunidades e subordinação dos pescadores como seus empregados. No que tange a comercialização a lógica do mercado vai progressivamente erodindo os saberes e práticas tradicionais. Logo, provoca alterações nos modos de viver dos pescadores, que vão sendo descaracterizados dentro da sua atividade e da sua comunidade.

$\mathrm{Na}$ região Nordeste o Turismo é apontado como principal atividade que disputa territórios com as comunidades de pescadores. É evidente que a valorização da paisagem associada aos corpos d'água tem atraído grandes empreendimentos turísticos para a região, como resorts. Contudo, tal instalação tem impactado o modo de viver tradicional das comunidades e frequentemente a "privatização" das praias públicas tem inviabilizado a atividade pesqueira.

Estão associadas a essa atividade os conflitos fundiários e a especulação imobiliária. Sendo os pescadores posseiros, por iniciativa dos próprios agentes públicos que visam a modernização são desapropriados de suas terras e alocados em áreas periféricas da cidade, por vezes longe dos pesqueiros. Aqueles que resistem sofrem ofensivas diárias e a negação de serviços básicos, como abastecimento de água e luz. A especulação imobiliária também age nesses contextos, aumentando o valor da terra e promovendo 0 oferecimento de serviços que não são acessíveis aos comunitários até que os mesmos não tenham mais condições de sobreviver no local e aceitem vender a terra.

Na região Nordeste merece destaque o que o MPP chama de hidronegócio, ou seja, a cessão de águas públicas para a iniciativa privada instalar empresas de aquicultura. Nesta região se evidencia o avanço do hidronegócio, sobretudo da carcinicultura que além de ocupar áreas que eram tradicionalmente exploradas pelos pescadores artesanais impedem o acesso desses sujeitos a importantes pesqueiros tradicionais.

Também é apontado o agravamento de disputas internas na pesca artesanal. Como foi dito a influência de atividades que propõe a modernização implica na erosão de "saberes tradicionais" e vínculos comunitários. Por consequência, existem casos em que os pescadores entram em conflito por territórios ou pela forma como o território é usado (esforço de pesca).

$\mathrm{Na}$ região Centro-Oeste o principal conflito decorre da configuração fundiária. Neste sentido o avanço do agronegócio sobre as comunidades tradicionais ocorre de forma ainda mais violenta. Também são incorporadas às fazendas as áreas de beira de rio, 0 que impede o acesso dos pescadores ao rio e seus pesqueiros.

Essas mesmas fazendas promovem outra atividade que entra em conflito com os territórios tradicionais de pesca - a pesca amadora. Essa atividade econômica promovida na região não é devidamente mensurada, mas as pesquisas apontam que competem com a pesca artesanal por pescado.

Nesta região também são apresentados conflitos com a atividade de mineração, que altera as características do território pesqueiro retirando dos pescadores condições de praticar a pesca.

$\mathrm{Na}$ região Sudeste efetivamente a urbanização chegou ao território pesqueiro, tanto que tem provocado em muitas pesquisas a discussão sobre o pescador urbano. As pesquisas apontam os conflitos estabelecidos entre território pesqueiro e a modernização do espaço. Neste sentido, além do avanço do tecido urbano e seus impactos cabe destacar os conflitos entre indústria e comunidades de pescadores, 0 
qual estabelece o embate entre desenvolvimento econômico e comunidades tradicionais (apresentadas pelos agentes do desenvolvimento como arcaicas e entraves para o progresso).

Conflitos fundiários também são apontados na região sudeste, sobretudo em casos de comunidades que resistem em seus territórios tradicionais. Contudo, frequentemente são despejadas e alocadas em periferias urbanas erodindo com a tradição comunitária e com os saberes da pesca.

Nesta região os Portos também ganham destaque quanto ao conflito com os territórios pesqueiros. Mais uma vez o moderno, com promessa de desenvolvimento, sobrepõe a tradicionalidade das comunidades e o direito de ser pescador artesanal. $O$ avanço dos portos é responsável pelo deslocamento de comunidades inteiras, bem como resulta no estabelecimento de áreas de exclusão da pesca.

Nos trabalhos também são apontados conflitos por território com a pesca industrial. Cabe frisar que esse conflito muitas vezes resulta em violência e perdas de apetrechos de pesca do pescador artesanal. A atuação da pesca industrial só termina quando os recursos são exauridos, o que impede a reprodução do território pesqueiro artesanal. As unidades de conservação criadas sobre os territórios dos pescadores também geram conflitos graves no que tange às normas de uso. Frequentemente os pescadores artesanais que nasceram no local e tem praticas tradicionais de manejo são tratados como infratores pelos gestores dessas unidades.

$\mathrm{Na}$ região Sul esse conflito com unidades de conservação é o mais evidente nos trabalhos analisados. Sobretudo o estabelecimento de parques em áreas onde estão situadas as comunidades impede a reprodução social do pescador em dois sentidos. Primeiro tem seu modo de vida impactado com normas que são alheias ao lugar e, com raras exceções, não são consultados na elaboração das regras a que são submetidos. Segundo por que o zoneamento das unidades costuma gerar áreas de exclusão da pesca, o que impede que os pescadores acessem pesqueiros que eram tradicionais.

Conflitos fundiários também ocorrem na região Sul, considerando que geralmente as áreas ocupadas pelas comunidades são "posses", o que lhes deixam sujeitos a desocupações em situações em que são propostos projetos públicos e/ou privados que prometem o desenvolvimento do potencial econômico do local.

$\mathrm{Na}$ região já começam a se evidenciar conflitos relacionados ao hidronegócio. Projetos de aquicultura estão sendo propostos com apoio do poder público sobre os territórios pesqueiros ou muito próximos. Contudo, a pesca industrial continua sendo uma forte atividade que compete por territórios pesqueiros. As organizações sociais de pescadores artesanais causam resistência a essa atividade econômica, contudo pouco tem conseguido bloquear o avanço dos barcos industriais sobre os seus territórios.

\section{Referências}

A análise das pesquisas realizadas sobre a pesca artesanal na Geografia aponta para a relação dialética entre os conceitos de ambiente e território. No artigo tentou-se distinguir as abordagens de "Territórios da Natureza e Natureza do Território" para evidenciar essa relação. Contudo, a provocação que se coloca no presente é como evidenciar conceitualmente esse híbrido está presente na complexidade do real.

Destacaram-se os principais impactos ambientais e conflitos por território por regiões brasileiras para enfatizar que existem distinções e variáveis em comum. Algo em comum 
é a configuração fundiária brasileira, que tem orientado os estudos em Geografia agrária, mas também se reflete na pesca artesanal. Cabe frisar que na região Norte as hidroelétricas e pesca comercial ganham destaque. Na região Nordeste se evidencia o avanço do turismo predatório e do hidronegócio. Na região Sudeste a expansão dos portos soma-se à urbanização e industrialização. Já na região Sul, a pesca artesanal está sujeita à expansão do agronegócio e à pressão da pesca industrial.

\section{Referências}

DE PAULA, C. Q. Gestão compartilhada dos territórios da pesca artesanal: Fórum Delta do Jacuí. 2013. 129p. Dissertação (Mestrado em Geografia). Programa de PósGraduação em Geografia da Universidade Federal do Rio Grande do Sul, Porto Alegre, 2013.

DE PAULA, C. Q. Tecendo uma Rede de Geografias da Pesca. In. SILVA, C. A.; DE PAULA, C. Q. (orgs) Brasil e Moçambique: diálogos geográficos sobre a pesca artesanal. Rio de Janeiro: Ed. Consequência, 2016.

DIEGUES, A. C. A pesca Construindo Sociedades. São Paulo: NUPAUB/USP, 2004.

HAESBAERT, R. O mito da desterritorialização: do "fim dos territórios" à multiterritorialidade. 3ª . ed. Rio de Janeiro: Bertrand Brasil, 2007.

RAFFESTIN, C. Por uma geografia do poder. São Paulo: Ática, 1993.

SACK, Robert. Human Territoriality: Its Theory and History. Cambridge: Cambridge University Press, 1986.

SANTOS, M. A Natureza do Espaço: Técnica e Tempo, Razão e Emoção. 4. ed. 2. reimpr. São Paulo: EDUSP, 2006.

SAQUET, M. A. A. Abordagens e concepções de território. 2ª ed. São Paulo: Expressão popula, 2010.

SILVA, C. N. Territorialidades e modo de vida de pescadores do Rio Ituquara, Breves - PA. Dissertação (Mestrado em Geografia) Universidade Federal do Pará. Belém, 2006.

SOUZA, M. L. D. O território: sobre espaço e poder, autonomia e desenvolvimento. In: CASTRO, I. E.; GOMES, P. C. D. C.; CORREAA, R. L. Geografia Conceitos e Temas. Rio de Janeiro: Bertrand, 1995.

SUERTEGARAY, D. M. A. Espaço Geográfico Uno e Multiplo. Scripta Nova, Barcelona, N.93, jul 2001. Disponível em www.ub.edu Acesso em 2010-06-12.

SUERTEGARAY, D. M. A. Geografia Física e Geomorfologia: Temas para Debate. Revista da ANPEGE, 2009A. 17-26.

SUERTEGARAY, D. M. A. Tempos Longos. Tempos Curtos. Na Análise da Natureza. Geografares, Vitória, jun 2002. 159-164. 